MAGE: A Method for Estimating the Maximum Possible Chemical Energy Content of UCG Product Gas for a Multistrata Coal Zone

C. Reid, E. Shafirovich, D. W. Camp

March 20, 2012 
This document was prepared as an account of work sponsored by an agency of the United States government. Neither the United States government nor Lawrence Livermore National Security, LLC, nor any of their employees makes any warranty, expressed or implied, or assumes any legal liability or responsibility for the accuracy, completeness, or usefulness of any information, apparatus, product, or process disclosed, or represents that its use would not infringe privately owned rights. Reference herein to any specific commercial product, process, or service by trade name, trademark, manufacturer, or otherwise does not necessarily constitute or imply its endorsement, recommendation, or favoring by the United States government or Lawrence Livermore National Security, LLC. The views and opinions of authors expressed herein do not necessarily state or reflect those of the United States government or Lawrence Livermore National Security, LLC, and shall not be used for advertising or product endorsement purposes.

This work performed under the auspices of the U.S. Department of Energy by Lawrence Livermore National Laboratory under Contract DE-AC52-07NA27344. 


\title{
MAGE: A Method for Estimating the Maximum Possible Chemical Energy Content of UCG Product Gas for a Multistrata Coal Zone
}

\author{
Charles Reid, Evgeny Shafirovich, David Camp
}

November 15, 2011

\section{Contents}

1 Introduction $\quad 2$

2 Single Stratum Energy Balance 2

2.1 Combustion Energy Release . . . . . . . . . . . . . . . . 3

2.1 .1 Heating Values . . . . . . . . . . . . . . . . . . . 3

2.1 .2 Coal . . . . . . . . . . . . . . . . . . 4

2.1 .3 Rock . . . . . . . . . . . . . . . . . 4

2.2 Energy Losses . . . . . . . . . . . . . . . . . . . . . 5

2.2 .1 Water . . . . . . . . . . . . . . 5

2.2 .2 Rubble . . . . . . . . . . . . . . . 8

2.2 .3 Dry Gas . . . . . . . . . . . . . . . . . . . 9

3 Multiple Strata Energy Balances $\quad 11$

4 Excel Calculations $\quad 11$

4.1 Excel Total Mass of Material . . . . . . . . . . . . . . . . . 11

4.2 Excel Heat of Reaction . . . . . . . . . . . . . . . . . . . 12

4.2.1 Heat of Reaction for Coal Strata . . . . . . . . . . . 12

4.2 .2 Heat of Reaction for Rock Strata . . . . . . . . . . . 12

4.3 Excel Water Losses . . . . . . . . . . . . . . . . . . . . . . . . 12

4.3.1 Water Losses for Coal Strata . . . . . . . . . . . . . 12

4.3.2 Water Losses for Rock Strata . . . . . . . . . . . . . . 13

4.4 Excel Rubble Losses . . . . . . . . . . . . . . . . . . . . . . . . 13

4.4.1 Rubble Losses for Coal Strata . . . . . . . . . . . . . . 13

4.4 .2 Rubble Losses for Rock Strata . . . . . . . . . . . . . 13

4.5 Excel Dry Product Gas Losses . . . . . . . . . . . . . . . . . 14

4.5.1 Dry Product Gas Losses for Coal Strata . . . . . . . . . . 14

4.6 Excel MAGE Number Calculation . . . . . . . . . . . . . . . . 14 


\section{Introduction}

Underground coal gasification (UCG) provides a methodology for extracting energy from underground coal seams that are inaccessible to surface or underground mining. UCG is a complex physical process, and many factors influence selection of sites. This report describes a novel method for estimating the upper bound on the extractable chemical energy content of UCG product gas per square meter of surface.

The material of interest underground is composed of various strata, or vertical portions of material that are horizontally homogeneous. A stratum of coal is also called a seam. These strata are stacked vertically and form multistrata, or zones. Each zone consists of either coal or rock material, and several assumptions are made about the system. It is assumed that there is no flux of water into the cavity, no heat loss to the surroundings, no gas loss to the surroundings, and $100 \%$ conversion of coal to gaseous products.

In order to determine the maximum extractable chemical energy content for a given square meter of surface, an energy balance is performed over each individual stratum beneath a given location, which yields an energy surplus or energy deficit; these can be summed up to provide an energy surplus or deficit for an entire zone, which can be used in determining the feasibility of UCG in a given area. The MAGE value is the cumulative energy surplus or energy deficit for all of the strata underneath a given square meter of surface.

\section{Single Stratum Energy Balance}

A bulk energy balance may be performed over a single stratum to determine the energy surplus or deficit for converting that material into byproducts of combustion. Surplus energy is in the form of chemical energy contained in the product gas. Deficit energy means energy must be fed into the system to convert materials into product gases. Coal seams will have an energy surplus, due to the energy released by the coal; rock will have an energy deficit, as it is an energy sink (it must be heated up and does not itself generate any heat). The bulk energy balance can be written as follows:

$\begin{aligned}\text { [chemical energy content of product gas }]= & \underbrace{[\text { energy release from combustion of material] }]}_{\text {Section } 2.1} \\ & -\underbrace{[\text { energy losses }]}_{\text {Section } 2.2}\end{aligned}$

Energy losses in the system are inherent, and come about because part of the energy contained in the coal must go toward heating up the system. The combustible material (coal only) provides energy to overcome those losses.

The enthalpies describing the energy state of the system can be expressed either extensively (as a total amount), or intensively (amount per unit mass). 
When the intensive forms are written, the equations will be written per unit mass of material, with units $\left[\frac{\text { energy }}{\text { mass of material }}\right]$. The equations apply to either coal or rock strata, so for a coal seam the intensive equations have units of $\left[\frac{\text { energy }}{\text { mass of coal }}\right]$ (where the coal is in the as-received state, the same as its state in the ground) and for a rock stratum the intensive equations have units of $\left[\frac{\text { energy }}{\text { mass of rock }}\right]$ (where the rock is in the same state as in the ground).

\subsection{Combustion Energy Release}

Because the system is a closed system at constant pressure, the energy balance is performed using enthalpy. The enthalpy release resulting from combustion of material is the enthalpy of reaction $\Delta H_{R}$ :

$$
\begin{aligned}
\Delta H_{R} & =H_{\text {products }}-H_{\text {reactants }} \\
& =\sum_{i=1}^{N_{s p, \text { prod }}} m_{i} h_{i}-\sum_{j=1}^{N_{\text {sp reac }}} m_{j} h_{j}
\end{aligned}
$$

where $H_{i}$ denotes the extensive enthalpy of species $i$ with units of [energy], and $h_{i}$ denotes the mass-specific enthalpy of species $i$ with units of $\left[\frac{\text { energy }}{\text { mass of } \mathrm{i}}\right]$. There are two materials being dealt with, and each are addressed below.

\subsubsection{Heating Values}

Before specifying the combustion energy released by rock or coal, the heating value should first be defined. The intensive heat of reaction of a material is equal in magnitude to the heating value of a fuel. However, there are two heating values: higher heating value (HHV) and lower heating vlaue (LHV). The higher heating value is a measure of the enthalpy change of the fuel if it were converted entirely to products of complete combustion, and all the steam condensed into liquid, while the lower heating value is the same but with the water kept in the form of steam. Heats of reaction have units of [ $\left.\frac{\text { energy }}{\text { mass coal }}\right]$ (where the coal may be as-received (AR) or dry, depending on the analysis).

The HHV is the net energy released by the fuel if it is taken from an initial state of room temperature fueld to a final state of complete combustion products at standard state. This requires that water be condensed out from the gaseous combustion products.

$$
\begin{aligned}
\Delta H_{R} & =H_{\text {products }}-H_{\text {reactants }} \\
\Delta H_{H H V} & =\left(H_{\text {non-water products }}^{\circ}+H_{\text {water (l) }}^{\circ}\right)-H_{\text {fuel }} \\
\Delta H_{L H V} & =\left(H_{\text {non-water products }}^{\circ}+H_{\text {water (v) }}^{\circ}\right)-H_{\text {fuel }}
\end{aligned}
$$

Another important distinction is whether the heating value is reported for as-received (AR) fuel, dry fuel, or dry ash-free (DAF) fuel; typically the heating 
value is reported for the as-received (AR) fuel, and the calculations described in this document will use the heating value of the as-received fuel. To convert from a dry heating value $H V_{d r y}$ (either lower or higher) or DAF heating value $H V_{d a f}$ to an AR heating value $H V_{A R}$ :

$$
\begin{aligned}
& H V_{A R}=\left(1-\omega_{\text {water in AR coal }}\right) H V_{d r y} \\
& H V_{A R}=\left(1-\omega_{\text {water in AR coal }}-\omega_{\text {ash in AR coal }}\right) H V_{d a f} .
\end{aligned}
$$

\subsubsection{Coal}

Within a coal seam, the enthalpy change comes only from coal reactions:

$$
\Delta H_{R}=\Delta H_{R, \text { coal }}
$$

where all quantities have units of [energy].

Converting the fuel into products of complete combustion will result in three things: first, dry combustion products, which will be considered separately from water; water from the combustion process ("combustion water"); and water originating as moisture originally in the fuel ("coal water"). The hydrogen and oxygen composing the combustion water originates from $\mathrm{H}$ and $\mathrm{O}$ atoms in the coal or from material injected into the cavity (this water is separate from moisture contained in the coal; see Section 2.2.1).

If the lower heating value is used, both the combustion water and the coal water are in a vapor state; if the higher heating value is used, both combustion water and coal water are in a liquid state. (Note that a dry or daf heating value could be used, but would require treating water and ash differently). The heats of reaction are given by:

$$
\begin{aligned}
\Delta H_{\mathrm{R}, \text { coal, } \mathrm{HHV}} & =\left(H_{\mathrm{dry} \text { combustion products }}+H_{\text {combustion water (l) }}+H_{\text {coal water (1) }}\right)-\left(H_{\mathrm{AR} \text { fuel }}\right) \\
& =m_{\mathrm{AR} \text { coal }} H H V_{\mathrm{AR} \text { coal }}
\end{aligned}
$$

if higher heating value is used, or, if lower heating value is used:

$$
\begin{aligned}
\Delta H_{\mathrm{R}, \text { coal, } \mathrm{LHV}} & =\left(H_{\mathrm{dry} \text { combustion products }}+H_{\text {combustion water (v) }}+H_{\text {coal water (v) }}\right)-\left(H_{\mathrm{AR} \text { fuel }}\right) \\
& =m_{\mathrm{AR} \text { coal }} L H V_{\mathrm{AR} \text { coal }}
\end{aligned}
$$

The choice of HHV or LHV as a basis does not ultimately matter, so long as it is consistent with the water enthalpy loss calculation in Section 2.2.1.

\subsubsection{Rock}

The heat released by combustion of rock material is assumed to be zero, so that the heat of reaction of rock has a higher heating value of zero:

$$
\Delta H_{\mathrm{R}, \text { rock, } \mathrm{HHV}}=0
$$


and a lower heating value that is negative (this is due to the fact that the liquid water must be vaporized to obtain the combustion products in the correct final state):

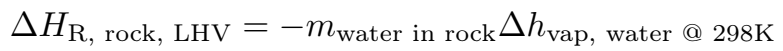

where the mass of water in the rock is given by

$$
m_{\text {water in rock }}=\omega_{\text {water in rock }} m_{\text {rock material }},
$$

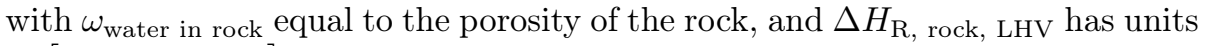
of $\left[\frac{\text { energy }}{\text { mass of material }}\right]$.

\section{$2.2 \quad$ Energy Losses}

If the process of extracting energy by oxidizing carbon contained in coal were perfectly efficient, no heat would be wasted - in which case, the energy surplus of the stratum would be equal to the heat contained in the coal. However, this is not realistic, as there is a large amount of material surrounding the coal that must also be heated.

There are three energy sinks in the system: water, rubble, and gas.

$$
[\text { energy losses }]=[\text { water losses }]+[\text { rubble losses }]+[\text { dry gas losses }]
$$

Each of these three sinks are analyzed in detail below.

\subsubsection{Water}

The first energy sink, water, has two different sources: some of the water comes from moisture in coal, and some comes from moisture in rock. The flux of water into the cavity due to the hydrology of the surrounding rock is ignored for the MAGE calculation.

The computation of energy spent heating water can be split into energy spent heating water from coal and energy spent heating water in the rock, as well as water resulting from combustion of the coal:

$$
\Delta H_{\text {water }}=\Delta H_{\text {coal water }}+\Delta H_{\text {rock water }}+\Delta H_{\text {combustion water }} .
$$

The enthalpy changes will each be treated below.

In order to compute the enthalpy change of the water inside the coal, the initial state of the water must be determined. This depends on the final state of water for the heating value used in computing the heat of reaction (see Section 2.1.2). If the final state of water is liquid (i.e. the higher heating vlaue is used), the enthalpy change of the coal-derived water becomes: 


$$
\begin{aligned}
\Delta H_{\text {coal water, HHV }=} & \Delta H_{\text {coal water }}\left(T_{o, \text { coal }}(l) \rightarrow T_{f, g a s}(v)\right) \\
= & m_{\text {water in AR coal }} \Delta h_{\text {coal water }, \mathrm{HHV}} \\
= & \Delta H_{\text {coal water }}\left(T_{o, \text { coal }} \rightarrow T_{\text {boil }}\right) \\
& +\Delta H_{\text {vap }, \text { water }}+\Delta H_{\text {coal steam }}\left(T_{\text {boil }} \rightarrow T_{f, g a s}\right) \\
= & m_{\text {water in AR coal }}\left[\int_{T_{\text {S.S. }}}^{T_{\text {boil }}} C_{p, \text { water }} d T\right. \\
& \left.+\Delta h_{\text {vap }, \text { water }}+\int_{T_{\text {boil }}}^{T_{f, g a s}} C_{p, \text { steam }} d T\right]
\end{aligned}
$$

where $T_{S . S}$. is the standard state temperature used in computing the heating value. If the final state of the water is vapor (the LHV is used), the enthalpy change becomes:

$$
\begin{aligned}
\Delta H_{\text {coal water }, \mathrm{LHV}} & =\Delta H_{\text {coal steam }}\left(T_{o, \text { coal }} \rightarrow T_{f, \text { gas }}\right) \\
& =m_{\text {water in AR coal }} \Delta h_{\text {coal water, LHV }} \\
& =m_{\text {water in AR coal }}\left[\int_{T_{o, \text { coal }}}^{T_{f, \text { gas }}} C_{p, \text { steam }} d T\right]
\end{aligned}
$$

The mass of coal water is equal to:

$$
m_{\text {water in AR coal }}=m_{\text {coal }} \omega_{\text {water in AR coal }}
$$

where $\omega$ denotes mass fraction and $m_{\text {coal }}$ denotes the mass of coal in-place. The mass of coal can be computed from information about the seam thickness:

$$
m_{\text {coal }}=(\text { area })(\text { seam thickness })\left(\rho_{\text {coal }}\right) .
$$

This can be expressed in an intensive form, with units of $\left[\frac{\text { energy }}{\text { mass of AR coal }}\right]$ :

$$
\begin{aligned}
\Delta h_{\text {coal water, HHV }}= & \omega_{\text {water in AR coal }}\left[\int_{T_{S . S .}}^{T_{\text {boil }}} C_{p, \text { water }} d T\right. \\
& \left.+\Delta h_{\text {vap }, \text { water }}+\int_{T_{\text {boil }}}^{T_{f, \text { gas }}} C_{p, \text { steam }} d T\right]
\end{aligned}
$$

or for LHV:

$$
\Delta h_{\text {coal water, LHV }}=\omega_{\text {water in AR coal }}\left[\int_{T_{S . S .}}^{T_{f, g a s}} C_{p, \text { steam }} d T\right] .
$$

As with the water losses due to coal water, the enthalpy change of the rock depends on whether the lower or higher heating value is used for rock material. 
The procedure is similar for rock and coal. The heating of rock water starts at an initial state equal to the final state as dictated by the heating value; if the HHV is used, the water begins as a liquid, and if the LHV is used, the water begins as steam. The rock water losses then become:

$$
\begin{aligned}
\Delta H_{\text {rock water, } \mathrm{HHV}=} & \Delta H_{\text {rock water }} \\
= & \Delta H_{\text {rock water }}\left(T_{o, \text { rock }} \rightarrow T_{\text {boil }}\right) \\
& +\Delta H_{\text {vap }, \text { water }}+\Delta H_{\text {rock water }}\left(T_{\text {boil }} \rightarrow T_{f, \text { gas }}\right) \\
= & m_{\text {water in rock }}\left[\int_{T_{o, \text { rock }}}^{T_{\text {boil }}} C_{p, \text { water }} d T+\Delta h_{\text {vap }, \text { water }}+\int_{T_{\text {boil }}}^{T_{f, g a s}} C_{p, \text { steam }} d T\right] .
\end{aligned}
$$

As before, the mass of rock water is computed as:

$$
m_{\text {rock water }}=\omega_{\text {water in rock }} m_{\text {rock }}
$$

with the mass of rock given by:

$$
m_{\text {rock }}=(\text { area })(\text { rock layer thickness })\left(\rho_{\text {rock }}\right) .
$$

The mass fraction of water in rock, $\omega_{\text {water in rock, }}$, is equal to the porosity of the rock, and is typically assumed to be $15 \%$ (or some other value, based on the rock type). The enthalpy equation can be expressed in an intensive form, with units of $\left[\frac{\text { energy }}{\text { mass of AR rock }}\right]$ :

$\Delta h_{\text {rock water }}=\omega_{\text {water in rock }}\left[\int_{T_{o, \text { rock }}}^{T_{\text {boil }}} C_{p, \text { water }} d T+\Delta h_{\text {vap }, \text { water }}+\int_{T_{\text {boil }}}^{T_{f, \text { gas }}} C_{p, \text { steam }} d T\right]$.

Because the intention of the calculation is to compute the maximum energy content per unit area, the area in the above formulas for $m_{\text {coal }}$ and $m_{\text {rock }}$ assume an area of $1 \mathrm{~m}^{2}$, with layer thickness as the only variable.

The combustion water results from burning dry coal, so it is essentially water coming from hydrogen and oxygen molecules either in the coal itself or in material injected into the underground cavity. The heat of combustion, added to the overall energy balance, assumes that the fuel releases energy, forms products of complete combustion (which include water), and brings the combustion products to $25 \mathrm{C}$. If the lower heating value is used, this means the fuel formed water vapor, and the vapor was brought down to $25 \mathrm{C}$ without being condensed. If the higher heating value is used, then the vapor is brought down to $25 \mathrm{C}$ and condensed. This means it must be re-vaporized when heating the combustion product gas ${ }^{1}$. However, one may make the assumption that there is a negligible amount of water in the effluent syngas in order to justify ignoring the combustion water enthalpy change.

\footnotetext{
${ }^{1}$ The correct way to calculate the enthalpy change due to water is as follows: (a) perform a hydrogen atom balance, then (b) perform an oxygen atom balance; (c) compute the composition of complete combustion products, rather than specifying them (technically, however, specifying the combustion products will change the heating value of the fuel, as it will change
} 
Thus $\Delta H_{\text {water }}$ has two forms, one for HHV:

$$
\begin{aligned}
\Delta H_{\text {water, HHV }}= & \Delta H_{\text {coal water, HHV }}+\Delta H_{\text {rock water, HHV }} \\
= & \omega_{\text {water in AR coal }} h_{\text {stratum }} \rho_{\text {coal }}\left[\int_{T_{S S}}^{T_{\text {boil }}} C_{p, \text { water }} d T\right. \\
& \left.+\Delta h_{\text {vap, water } @ 373 \mathrm{~K}}+\int_{T_{\text {boil }}}^{T_{f, \text { gas }}} C_{p, \text { steam }} d T\right] \\
& +\omega_{\text {water in rock }} h_{\text {stratum }} \rho_{\text {rock }}\left[\int_{T_{o, \text { rock }}}^{T_{\text {boil }}} C_{p, \text { water }} d T\right. \\
& \left.+\Delta h_{\mathrm{vap}, \text { water } @ 373 \mathrm{~K}}+\int_{T_{\text {boil }}}^{T_{f, \text { gas }}} C_{p, \text { steam }} d T\right]
\end{aligned}
$$

and the other for LHV:

$$
\begin{aligned}
& \Delta H_{\text {water, LHV }}=\Delta H_{\text {coal water, LHV }}+\Delta H_{\text {rock water, LHV }} \\
& =\omega_{\text {water in AR coal }} h_{\text {stratum }} \rho_{\text {coal }}\left[\int_{T_{S S}}^{T_{f, g a s}} C_{p, \text { steam }} d T\right] \\
& +\omega_{\text {water in rock }} h_{\text {stratum }} \rho_{\text {rock }}\left[\int_{T_{S S}}^{T_{f, g a s}} C_{p, \text { steam }} d T\right]
\end{aligned}
$$

where $h_{\text {stratum }}$ is the height, or thickness, of the stratum, and $T_{S S}$ is the standard-state temperature used to compute the heating value of the fuel.

\subsubsection{Rubble}

The second energy sink is rubble. The rubble that forms during underground coal gasification consists of two parts: first, rubble from rock layers. If a layer of rock lies between two layers of coal, it is assumed that the rock will crumble when the lower layer of coal gasifies, and that the rock that crumbles will form rubble. Second, the rubble is also composed of ash left behind by the gasified coal. Both the rock and the ash will reach the same final temperature of $T_{\text {rubble }}=T_{f, \text { rock }}=$ $T_{f, a s h}$. Thus the enthalpy expended on heating the rubble, assuming rock and

the final enthalpy of the combustion products). These atom balances would yield the amount of water evolved from the dry coal via combustion, and (separately) the amount of water that was originally moisture in the coal. 
ash stay as solids, can be expressed as:

$$
\begin{aligned}
\Delta H_{\text {rubble }} & =\Delta H_{\text {rock }}+\Delta H_{\text {ash }} \\
& =m_{\text {rock }} \Delta h_{\text {rock }}+m_{\text {ash }} \Delta h_{\text {ash }} \\
& =\Delta H_{\text {rock }}\left(T_{o, \text { rock }} \rightarrow T_{\text {rubble }}\right)+\Delta H_{\text {ash }}\left(T_{o, \text { coal }} \rightarrow T_{\text {rubble }}\right) \\
& =m_{\text {rock }} \int_{T_{o, \text { rock }}}^{T_{\text {rubble }}} C_{p, \text { rock }} d T+m_{\text {ash }} \int_{T_{o, \text { coal }}}^{T_{\text {rubble }}} C_{p, \text { ash }} d T .
\end{aligned}
$$

Expressing this in an intensive form with units of $\left[\frac{\text { energy }}{\text { mass of AR coal }}\right]$ yields:

$$
\begin{array}{r}
\Delta h_{\text {rubble }}=\omega_{\text {rock in material }}\left[\int_{T_{o, \text { rock }}}^{T_{\text {rubble }}} C_{p, \text { rock }} d T\right] \\
+\omega_{\text {ash in material }}\left[\int_{T_{o, \text { coal }}}^{T_{\text {rubble }}} C_{p, \text { ash }} d T\right] .
\end{array}
$$

The mass of rock is given by equation 21 above; the mass of ash is given by:

$$
m_{\text {ash }}=\omega_{\text {ash in coal }} m_{\text {coal }}
$$

and $m_{\text {coal }}$ is given by equation 16 above.

\subsubsection{Dry Gas}

The third sink is the dry gas product of UCG. The coal is assumed to undergo complete combustion, and the energy released by this combustion process results in products at standard state (with temperature 25 degrees Celsius). Thus the dry gas starts at this standard state temperature, and is heated up to the final gas temperature $T_{f, g a s}$ :

$$
\begin{aligned}
\Delta H_{\text {dry product gas }} & =\Delta H_{\text {dry product gas }}\left(T_{S S} \rightarrow T_{f, \text { gas }}\right) \\
& =m_{\text {dry gas }} \Delta h_{\text {dry gas }}
\end{aligned}
$$

The mass of dry product gas generated from a coal strata can be obtained by starting with the number of moles of dry product gas:

$$
m_{\mathrm{dry} \text { gas }}=M W_{\mathrm{dry} \text { gas mix }} n_{\mathrm{dry} \text { gas }} .
$$

The number of moles of dry gas generated from the coal can be computed using a carbon balance.

It is known that carbon comes from coal and only coal, so an elemental balance on $\mathrm{C}$ yields:

$$
\text { moles } \mathrm{C} \text { in dry gas }=\text { moles } \mathrm{C} \text { in } \mathrm{AR} \text { coal }
$$

and, multiplying by $\frac{\text { mol dry gas }}{\text { mol dry gas }}$ and rearranging, 


$$
\text { mol } \left.\mathrm{C} \text { in } \mathrm{AR} \text { coal }=\left(\frac{\text { mol C in dry gas }}{\text { mol dry gas }}\right) \text { (mol dry gas }\right) .
$$

The ratio is equal to:

$$
\frac{\mathrm{mol} \mathrm{C} \text { in dry gas }}{\text { mol dry gas }}=\sum_{i=1}^{N_{s p}} x_{i} N_{C, i}
$$

where $N_{C, i}$ is the number of carbon atoms in species $i$ and $x_{i}$ is the mole fraction of species $i$. Rearranging to find the quantity of interest,

$$
\text { mol dry gas }=\left(\frac{\text { mol } \mathrm{C} \text { in dry gas }}{\text { mol dry gas }}\right)^{-1}(\text { mol } \mathrm{C} \text { in AR coal })
$$

or

$$
n_{\text {dry gas }}=\left(\frac{1}{\sum_{i} x_{i} N_{C, i}}\right) n_{C, \text { coal }}
$$

with units:

$$
\text { [mol dry gas] . }
$$

The moles of $\mathrm{C}$ in the as-received coal can be computed as follows:

$$
n_{C, \text { coal }}=\frac{m_{\text {coal }} \omega_{d a f} \omega_{C, d a f}}{M W_{C}}
$$

where $\omega_{C, d a f}$ is the weight percent of $\mathrm{C}$ in the daf coal. This relation has units:

$$
[\mathrm{mol} \mathrm{C}]=[\mathrm{kg} \text { AR coal }]\left[\frac{\mathrm{kg} \mathrm{daf} \mathrm{coal}}{\mathrm{kg} \mathrm{AR} \mathrm{coal}}\right]\left[\frac{\mathrm{kg} \mathrm{C}}{\mathrm{kg} \text { daf coal }}\right]\left[\frac{\mathrm{mol} \mathrm{C}}{\mathrm{kg} \mathrm{C}}\right] .
$$

Finally, the mixture molecular weight of the dry gas mixture is:

$$
M W_{m i x}=\sum_{i} x_{i} M W_{i} .
$$

Now the relation 37 can be plugged into equation 35 , and equations 35 and 38 can be plugged into equation 30 , to yield the equation for mass of dry gas:

$$
m_{\mathrm{dry} \mathrm{gas}}=m_{\mathrm{AR} \text { coal }} \omega_{\text {daf }} \omega_{C, \text { daf }}\left(\frac{M W_{\mathrm{dry} \text { gas }}}{M W_{\mathrm{C}}}\right)\left(\sum_{i} x_{i} N_{C, i}\right) .
$$

The enthalpy change of the dry gas is simple to calculate:

$$
\begin{aligned}
\Delta h_{\mathrm{dry} \mathrm{gas}} & =\int_{T_{S S}}^{T_{f, g a s}} C_{p, \text { dry gas }} d T \\
& \approx C_{p, \text { dry gas }}\left(T_{f, \text { gas }}-T_{S S}\right) .
\end{aligned}
$$


Note, however, that this has units of [energy/mass dry gas]. This must be multiplied by $m_{\text {dry gas }} / m_{\mathrm{AR}}$ coal to yield units of [energy/mass AR material]:

$$
\begin{gathered}
\Delta h_{\text {dry gas }}=\omega_{\text {daf }} \omega_{C, \text { daf }}\left(\frac{M W_{\text {dry gas }}}{M W_{\mathrm{C}}}\right)\left(\sum_{i} x_{i} N_{C, i}\right) \times \\
C_{p, \text { dry gas }}\left(T_{f, \text { gas }}-T_{S S}\right) .
\end{gathered}
$$

This yields $H_{\mathrm{dry}}$ product gas when multiplied by $m_{\mathrm{AR} \text { coal }}$.

\section{Multiple Strata Energy Balances}

Each MAGE calculation determines the chemical enthalpy available in the product gas after losses. Chemical enthalpy values for each stratum can be summed vertically over a zone to determine the net energy available on a per square meter basis for the entire zone:

$$
\begin{aligned}
& \text { [net chemical energy content of product gas }] \\
& =\sum_{k}^{N_{\text {stratum }}}[\text { energy release from combustion of material }] \\
& +\sum_{k=1}^{N_{\text {stratum }}}[\text { energy losses }] .
\end{aligned}
$$

\section{Excel Calculations}

The calculations being performed in Excel are described below.

\subsection{Excel Total Mass of Material}

Each of the energy terms below is given on a per mass of as-received (AR) material basis. For a coal stratum, this is on a per $\mathrm{kg}$ of AR coal basis; for a rock stratum, this is on a per $\mathrm{kg}$ of $\mathrm{AR}$ rock basis. The total mass of $\mathrm{AR}$ material, in turn, is computed on a per square meter basis, since that is the basis of the final reported MAGE number. The mass of AR material is computed for each strata based on the following formula:

$$
m_{\text {stratum }}=\rho_{\text {stratum }} h_{\text {stratum }} A_{\text {stratum }}
$$

where $\rho_{\text {stratum }}$ is the density of the material in the stratum; $h_{\text {stratum }}$ is the height (thickness) of the stratum; and $A_{\text {stratum }}$ is the area, which in this case is a $1 \mathrm{~m}^{2}$ basis area. This mass is multiplied by each $\Delta h$ given below to give the per-area enthalpy change $\Delta \hat{H}$ (hat denotes per area basis). 


\subsection{Excel Heat of Reaction}

\subsubsection{Heat of Reaction for Coal Strata}

For coal strata, the reported LHV (not HHV) for the coal seam is used. This yields the heat of reaction, per unit mass of AR coal material:

$$
\Delta h_{\mathrm{R}, \text { coal, } \mathrm{LHV}}=L H V_{\mathrm{AR}} \text { coal }
$$

with units:

$$
\left[\frac{\text { energy }}{\text { mass of AR material }}\right]=\left[\frac{\text { energy }}{\text { mass of AR coal }}\right]
$$

\subsubsection{Heat of Reaction for Rock Strata}

For rock strata, the HHV, not the LHV, is used. This makes the heat of reaction 0 :

$$
\Delta h_{\mathrm{R}, \text { rock, } \mathrm{HHV}}=0
$$

with units:

$$
\left[\frac{\text { energy }}{\text { mass of AR material }}\right] \text {. }
$$

\subsection{Excel Water Losses}

\subsubsection{Water Losses for Coal Strata}

For coal strata, the water losses are computed using an initial state consistent with the final state of water using the LHV (water vapor).

$$
\begin{aligned}
\Delta h_{\text {water losses }} & =\Delta h_{\text {coal water, LHV }} \\
& =\omega_{\text {water in AR coal }}\left(h_{\text {steam } @ T_{f, \text { gas }}}-h_{\text {steam } @ T_{S S}}\right) \\
& \approx \omega_{\text {water in AR coal }} C_{p, \text { steam }}\left(T_{f, \text { gas }}-T_{S S}\right)
\end{aligned}
$$

with units:

$\left[\frac{\text { energy }}{\text { mass of AR material }}\right]=\left[\frac{\text { mass of water }}{\text { mass of AR coal }}\right]\left[\frac{\text { energy }}{\text { mass of water } \cdot \text { temperature }}\right]$ [temperature] NOTE: This procedure is an (incorrect) approximation; see Section 2.2.1 for more information about the correct procedure. 


\subsubsection{Water Losses for Rock Strata}

The rock strata water losses are computed to be consistent with the use of HHV (Section 4.2.2) for computing rock heat of reaction. The final state is liquid water, making the enthalpy change:

$$
\begin{aligned}
\Delta h_{\text {water losses }} & =\Delta h_{\text {rock water, HHV }} \\
& =\omega_{\text {water in AR rock }}\left(h_{\text {steam } @ T_{f, g a s}}-h_{\text {water(l)@ } \left.T_{S S}\right)}\right.
\end{aligned}
$$

and the enthalpies of water obtained directly from the NIST WebBook. Note that if the LHV of rock (which is negative) were used, the initial state of the system would be the enthalpy of water vapor at $T_{S S}$; in this case, the differences in both the heating value and the initial enthalpy would balance, and the enthalpy change would be exactly the same as was computed using the HHV.

\subsection{Excel Rubble Losses}

\subsubsection{Rubble Losses for Coal Strata}

Coal strata contain ash, which contributes to the rubble. The enthalpy required to heat the ash in the coal is:

$$
\begin{aligned}
\Delta h_{\text {rubble losses }} & =\Delta h_{\text {ash }} \\
& =\omega_{\text {ash in AR coal }}\left(h_{\text {ash } @ T_{f, \text { rubble }}}-h_{\text {ash } @ T_{o, \text { coal }}}\right) \\
& \approx \omega_{\text {ash in AR coal }} C_{p, \text { ash }}\left(T_{f, \text { rubble }}-T_{o, \text { coal }}\right)
\end{aligned}
$$

with units:

$\left[\frac{\text { energy }}{\text { mass of AR material }}\right]=\left[\frac{\text { mass of ash }}{\text { mass of AR coal }}\right]\left[\frac{\text { energy }}{\text { mass of ash } \cdot \text { temperature }}\right]$ [temperature $]$

\subsubsection{Rubble Losses for Rock Strata}

Rock strata contain rock that must be heated up to the final rubble temperature.

$$
\begin{aligned}
& \Delta h_{\text {rubble losses }}=\Delta h_{\text {rock }} \\
& =\omega_{\text {rock }}\left(h_{\text {rock@ } @ T_{f, \text { rubble }}}-h_{\text {rock } @ T_{o, \text { coal }}}\right) \\
& \approx \omega_{\text {rock }} C_{p, \text { rock }}\left(T_{f, \text { rubble }}-T_{o, \text { coal }}\right)
\end{aligned}
$$

with units:

$\left[\frac{\text { energy }}{\text { mass of AR material }}\right]=\left[\frac{\text { mass of rock }}{\text { mass of AR rock }}\right]\left[\frac{\text { energy }}{\text { mass of rock } \cdot \text { temperature }}\right]$ [temperature] 


\subsection{Excel Dry Product Gas Losses}

\subsubsection{Dry Product Gas Losses for Coal Strata}

Computing the enthalpy losses due to the heating of dry product gases requires performing a somewhat detailed atom balance to determine the mass of product gas that would be formed from gasification. This cannot be done by assuming the mass of product gas is equal to the mass of DAF coal, since the product gas does not contain the same material. Instead, it is known that the only source of carbon is the coal, and so a carbon atom balance will compute the maximum amount of product gas that can be produced (given the user-specified product gas composition, and assuming that any hydrogen and oxygen are supplied through the injection point). Note that technically atom balances should also be performed on $\mathrm{H}$ and $\mathrm{O}$ (see Section 2.2.1 above). The enthalpy change for the dry product gas heating up per mass of dry product gas is given by equation 41. However, this equation is much more useful when expressed on a per mass of AR material basis, as in equation 42:

$$
\begin{gathered}
\Delta h_{\text {dry gas losses }}=\omega_{\text {daf }} \omega_{C, \text { daf }}\left(\frac{M W_{\text {dry gas }}}{M W_{\mathrm{C}}}\right)\left(\sum_{i} x_{i} N_{C, i}\right) \times \\
C_{p, \text { dry gas }}\left(T_{f, \text { gas }}-T_{S S}\right)
\end{gathered}
$$

with units:

$$
\begin{aligned}
{\left[\frac{\text { energy }}{\text { mass of AR material }}\right]=} & {\left[\frac{\mathrm{kg} \text { daf coal }}{\mathrm{kg} \text { AR coal }}\right]\left[\frac{\mathrm{kg} \mathrm{C}}{\mathrm{kg} \text { daf coal }}\right]\left[\frac{\mathrm{mol} \mathrm{C}}{\mathrm{kg} \mathrm{C}}\right] \times } \\
& {\left[\frac{\mathrm{mol} \mathrm{C} \text { in dry gas }}{\text { mol C in AR coal }}\right]\left[\frac{\text { mol dry gas }}{\text { mol C in dry gas }}\right]\left[\frac{\mathrm{kg} \text { dry gas }}{\text { mol dry gas }}\right] }
\end{aligned}
$$

\subsection{Excel MAGE Number Calculation}

The final MAGE number depends upon the mass of material in each stratum, as well as the mass-specific enthalpy changes:

$$
\begin{aligned}
\text { MAGE } & =\Delta \hat{H}_{\text {material }} \\
& =\sum_{j=1}^{N_{\text {strata }}} m_{j}\left(\Delta h_{R}-\Delta h_{\text {water losses }}-\Delta h_{\text {rubble losses }}-\Delta h_{\text {dry gas lo } \$ 569)}\right.
\end{aligned}
$$

and has units of:

$$
\left[\frac{\text { energy }}{\text { area }}\right]
$$

